ELORE (ISSN 1456-3010), vol. $16-1 / 2009$.

Julkaisija: Suomen Kansantietouden Tutkijain Seura ry.

[http://www.elore.fi/arkisto/1_09/art_kupiainen_1_09.pdf]

ARTIKKELIIN LITTTVÄ ELOKUVA

[http://www.elore.fi/arkisto/1_09/kupiainen.mov]

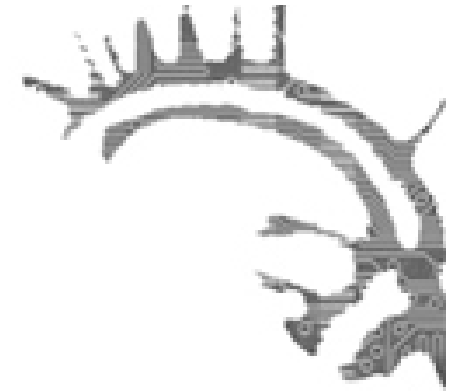

\title{
VARASTETTU MUSEO, VARASTETTU PERINNE - KYSYMYKSIÄ KULTTUURIPERINNÖN SUOJAAMISESTA MELANESIASSA
}

\author{
$\underline{\text { Jari Kupiainen }}$
}

Käsittelen tässä artikkelissa ongelmia, joihin en esitä yksiselitteisiä vastauksia. Lähinnä Salomonsaarten kulttuuriperinnön säilyttämisen vaikeaa tilaa tarkastelevan kuvauksen rinnalla tarkastelen yleisiä kysymyksiä, jotka liittyvät kulttuuriaineksen, esinekulttuurin ja suullisen perintötiedon suojaamiseen. Artikkelini tutkimuskysymys on eräänlainen metakysymys: kuinka ja millaisin menetelmin tekstissä kuvattavaa tilannetta ja asetelmaa tulisi tutkia sekä kulttuuritieteellisestä tutkijapositiosta lähestyä ja tarkastella? Salomonsaarilla perinteen suojaamista koskeva nykyaikainen lainsäädäntö on varsin puutteellinen, eikä valtiolla ole toimivaa valvontajärjestelmää perinneaineksen suojaamiseksi erilaisilta väärinkäytöiltä. Tarkastelen erityisesti Salomonsaarten Kansallismuseota (National Museum of Solomon Islands) Honiarassa, Salomonsaarten pääkaupungissa. Olen työskennellyt museon kokoelmien parissa vuosina 1996, 1998 ja 2007, jolloin olen oman tutkimustyöni ohessa ja osana myös dokumentoinut eri tavoin museon kokoelmien kulloistakin tilaa ja museon yleistä tilannetta.

\section{KANSALLISEN KULTTUURIN HISTORIALLINEN KONTEKSTI}

Noin tuhannesta saaresta koostuva, maantieteellisesti laaja Salomonsaarten alue tuli vaiheittain osaksi brittiläistä siirtomaahallintoa 1800-luvun viimeisinä vuosina, jolloin perustettiin Brittiläinen Salomonsaarten Protektoraatti (BSIP). Salomonsaaret itsenäistyi vuonna 1978 ja maan nykyinen väkiluku on noin 500 000. Alueen väestö puhuu - laskutapa vaihtelee - vajaata sataa kieltä (vrt. SIL 2009) ja koostuu karkeasti ottaen yhtä monesta etnisestä paikalliskulttuurista. Niistä valtaosa kuuluu melanesialaisiin ja 
lähinnä ulkosaarilla asuvat ryhmät (n. $4 \%$ väestöstä) kuuluvat polynesialaisiin kulttuureihin. Alkuperäisväestöjen lisäksi Salomonsaarilla asuu jonkin verran kiribatilais-, kiinalais- ja eurooppalaistaustaisia ryhmiä.

Siirtomaahallinnon rakentuminen 1900-luvun alkuvuosikymmeninä oli hidasta ja kulki käsi kädessä kristillisen lähetystyön etenemisen kanssa. Kristinuskoon kääntyminen oli perusedellytys siirtomaahallinnon perustamiselle, sillä kristillinen kulttuurinmuutos merkitsi käytännössä perinteisen sodankäynnin päättymistä, keskeisten kulttuuristen käytäntöjen hylkäämistä ja ryhmien sosiaalista uudelleenorganisoitumista siirtomaahallinnon tarpeisiin. Joillakin saarilla siirryttiin kristinuskon myötä sisämaan vuoristojen pienistä yhdyskunnista rannikoille perustettuihin kyliin, joissa kristillinen päivärytmi kytkettiin paikalliseen plantaasitalouteen osana siirtomaahallinnon rakentumista (mm. Uuden Georgian saariryhmä; esim. Hviding 1996; Kupiainen 2000; Thomas 1992). Hajallaan eläneistä perheryhmistä muodostettiin heimoja sekä niille päälliköitä ja pääliköiden päälliköitä (paramount chief) afrikkalaisten siirtomaahallinnon mallien mukaisesti, kuten meneteltiin Malaitan saarella (ks. esim. Keesing 1987; 1992). Kyliä, heimoja ja päälliköitä tarvittiin brittiläisen epäsuoran hallintomallin (indirect rule) paikallisiksi välikappaleiksi, sillä brittihallintoa edustivat protektoraatissa vain yksittäiset virkailijat, jotka käyttivät paikallisia edusmiehiä eli päälliköitä paikallishallinnon ylläpitämiseen.

Salomonsaarten nykyhistoriaan vaikutti ehkäpä eniten toinen maailmansota, jolloin saariryhmä ja erityisesti Guadalcanalin saari joutuivat Tyynenmeren taistelujen keskeiseksi näyttämöksi. Aluksi saaret miehitti Japanin armeija, joka alkoi rakentaa Guadalcanalin saarelle suurta lentokenttää (sittemmin Hendersonin lentokenttä) hallitsemaan koko läntisen Tyynenmeren aluetta ja muun ohella pohjoista Australiaa. Yhdysvaltain johtama liittoutuneiden armeija teki suuren maihinnousun Guadalcanaliin syyskuussa 1942. Saariryhmä muuttui veriseksi sotanäyttämöksi, jossa sekä liittoutuneet että Japani kokivat raskaita tappioita. Salomonsaarten paikalliset asukkaat seurasivat sotatapahtumia sivusta, mutta joitakin paikallisia työskenteli Japanin tai liittoutuneiden armeijoiden avustajina ja tiedustelijoina. Vain muutama salomonsaarelainen kuoli sodassa. (Esim. Boutilier 1990.)

Sodanjälkeinen paluu brittihallinnon arkeen oli traumaattinen. Liittoutuneiden sotilaat olivat kohdelleet paikallista väestöä ystävällisesti ja tasa-arvoisesti, kun rasistinen brittihallinto oli puolestaan paennut sodan alta ja osoittanut kyvyttömyytensä saarelaisten suojelemiseen ulkoisilta uhkilta. Useilla saarilla muodostui sodanjälkeisinä vuosina siirtomaahallintoa arvostelleita protestiliikkeitä. Niistä tunnetuin oli Malaitan saarelta käynnistynyt Maasina Ruru, joka pakotti britit moniin hallinnollisiin ja lainsäädännöllisiin uudistuksiin (esim. Burt 1994; Keesing 1992; Laracy 1983). Brittihallinnon aiempi keskuspaikka ja pääkaupunki Tulagin saarella oli tuhottu japanilaisten pommituksissa, ja uutta pääkaupunkia Honiaraa alettiin rakentaa liittoutuneiden jättämien parakkien ympärille Guadalcanalin saarelle Hendersonin lentokentän läheisyyteen (esim. Bellam 1970; Kupiainen 2000, 128-137).

Honiara sällyi pienenä puutarhakaupunkina aina 1970-luvun puoliväliin ja itsenäistymiseen (1978) asti, jolloin käynnistyi nykyhetkeen jatkunut kaupungistuminen ja hallitsematon muuttoliike saariryhmän eri kolkista pääkaupunkiin. Samalla muo- 
JARI KUPIAINEN

dostui nykyään yleinen käytäntö, jossa kotisaarilla ja Honiarassa vietetään vuorotellen pitkähköjä jaksoja ja perheet ovat jakaantuneet kaupunkiin ja kotisaarille samanaikaisesti (esim. Chapman 1992; Kupiainen 2000). Honiaran väkiluku moninkertaistui 1990-luvun loppuun tultaessa, jolloin arvio kaupungin väkiluvusta oli noin 80000 (ks. Kupiainen 2000).

Kaupunkiin muuttajat valtasivat koko ajan lisää alueita Honiaran liepeiltä ja rakensivat omia kaupunkikyliään paikallisten maanomistajien kasvavaksi harmiksi. Guadalcanalin maanomistajat perustivat vuonna 1999 sissiarmeijan häätämään muuttajia pois Honiarasta. Tästä käynnistyi monivuotinen aseellinen konflikti ja Guadalcanaliin keskittynyt sisällissota, jonka seurauksena ainakin 20000 Honiaran asukasta joutui jättämään kotinsa ja pakenemaan kotisaarilleen. Konflikti rakentui erityisesti Guadalcanalin ja viereisen Malaitan saaren väestöjen välille. Malaitalaiset perustivat oman sissiarmeijan, joka kesäkuussa 2000 miehitti Honiaran sekä vangitsi maan hallituksen pakottaen sen eroamaan. Konfliktin syventyessä myös sissien nimeämä hallitus menetti kontrollin tilanteeseen ja etenkin tapahtumien keskipisteenä ollut Honiara muuttui sissiryhmien partioimaksi taisteluvyöhykkeeksi, mutta muuallakin taisteltiin.

Lopulta otteensa valtion tilanteeseen täysin menettänyt hallitus kutsui ympäröivät valtiot apuun ja elokuussa 2003 Australian ja Uuden Seelannin armeijoiden johtama Regional Assistance Mission to Solomon Islands (RAMSI) miehitti Salomonsaaret. Sittemmin RAMSI:n sotilasjoukot pidättivät sissipäälliköt ja rauhoittivat väkivaltaisen tilanteen. RAMSI:n sotilasmiehitys jatkuu edelleen ja sen on arvioitu kestävän vielä useita vuosia. YK ei ole osallinen tässä rauhanturvaamisen prosessissa. (Fraenkel 2005; Kabutaulaka 2005; Moore 2005.) Kirjoituksen ajankohtana maaliskuussa 2009 Honiaran jälleenrakentaminen ja elpyminen etenevät ja talous on toipumassa, joskin hitaasti. Ryhmien väliset jännitteet kytevät, mutta RAMSI:n läsnäolo rauhoittaa. Myös turistit ovat palaamassa Salomonsaarille, uusimpana kohderyhmänä surffaajat.

\section{KONFLIKTEISTA KULTTUURIPERINNÖN SUOJAAMISEEN:}

\section{LÄNSIMAISEN KERÄILYINTRESSIN VAIHEITA JA VAIKUTUKSIA SALOMONSAARILLA}

Alvarho de Mendañan ajoista (1569) alkaen eurooppalaiset vierailijat ovat olleet kiinnostuneita saarelaisten esinekulttuurista: aseista, koruista, patsaista ja kaikenlaisesta muustakin keräiltävästä, jota on voitu esitellä näytteinä ja todisteina eksoottisista paikoista. Toiseen maailmansotaan tultaessa oli jo muodostunut Salomonsaarten esinekokoelmia eri puolille maailmaa museoihin ja yksityisiin koteihin, mutta keskeisiä kokoelmia oli myös Salomonsaarilla brittihallinnon virkailijoiden ja muiden eurooppalaisten hallussa. Osa näistä sotaa edeltäneistä kokoelmista päätyi eurooppalaisiin, yhdysvaltalaisiin ja australialaisiin museoihin, etenkin British Museumiin, mutta laajoja kokoelmia tuhoutui Tulagin pommituksissa ja muissa sotatapahtumissa. Lisäksi kristillisten lähetyssaarnaajien tavanomainen menettelytapa oli, että kristinuskoon kääntyvien tuli osana kääntymystä tuhota, polttaa tai muulla tavoin hankkiutua eroon 
esikristillisen ajan uskonnollisesta esineistöstä kääntymyksen vakuudeksi. Tämän vuoksi perinteisiin uskontoihin liittyvää vanhaa esinekulttuuria Salomonsaarilta on nykyisin kansainvälisissä museoissa ja julkisissa kokoelmissa suhteellisen niukasti ja joiltakin saarilta tuskin ollenkaan. (Ks. Kupiainen 2000; vrt. esim. Gosden \& Knowles 2001; O’Hanlon \& Welsch 2000.) Kun tässä tekstissä puhun "vanhoista" esineistä, tarkoitan sellaisia kulttuuriesineitä, jotka paikallisesti ajoittuvat aikaan ennen kristillistä kulttuurinmuutosta. Eri yhteisöissä tämä muutos on tapahtunut eri aikoina.

Toisen maailmansodan aikana sotilaiden kanssa käyty vilkas esineiden ja "matkamuistojen" kauppa siirsi lukuisat salomonsaarelaisyhteisöt modernin rahatalouden piiriin ainakin kulttuuriesineisiin kohdistuneen länsimaisen kiinnostuksen osalta. Samalla muodostuivat myöhempien käsityömarkkinoiden päälinjat, joissa huomio keskittyi pienehköjen, helposti pakattavien ja kuljetettavien esineiden valmistukseen. Lisäksi tuolloin käynnistyi meriaiheisten puuveistosten tekeminen ja myös simpukankuorikoristelun lisäämiseen kiinnitettiin huomiota. (Ks. lisää Kupiainen 2000, 77-82.)

Sodan jälkeisinä vuosina uudelleen käynnistetyn siirtomaahallinnon virkailijat alkoivat osoittaa kasvavaa kiinnostusta pysyvän kulttuuriesinekokoelman rakentamiseksi, ja "Honiaran museon" perustamista alettiin valmistella. Vuonna 1952 käynnistetty Honiaran museo toimi vaihtuvissa tiloissa aina vuoteen 1969 saakka, jolloin ensimmäiset nykyisistä museorakennuksista valmistuivat. Tuossa yhteydessä museosta alettiin puhua Salomonsaarten kansallismuseona, ja Salomonsaarten itsenäistymisestä (1978) lähtien National Museum of Solomon Islands on toiminut valtion keskeisenä kulttuuriperinnön suojelemisen ja säilyttämisen instituutiona nykyhetkeen saakka. Koko toimintansa ajan kansallismuseo on kuitenkin kärsinyt resurssien ja pätevän henkilökunnan puutteesta, mikä on tehokkaasti jarruttanut museon perustehtävien hoitamista. (Ks. lisää Foanaota 1991, 107-112; Kupiainen 2000, 137-138.)

Etnisen konfliktin aikana 1999-2003 myös kansallismuseon keskeinen henkilöstö joutui pakenemaan Honiarasta ja museo oli jaksoittain suljettuna. Tuona aikana museo joutui monien tihutöiden kohteeksi. Esimerkiksi näyttelytilaan tunkeuduttiin, paikkoja sotkettiin ja yksittäisiä esineitä varastettiin. RAMSI:n miehityksen alkamisen jälkeenkin kansallismuseo joutui vahingonteon kohteeksi. Vuosina 2004-2005 museon varastoon murtauduttiin lyhyen ajan sisällä neljä kertaa ja noissa murroissa varastettiin keskeisiä osia museon arvokkaimmista kokoelmista. Museon johtajan Lawrence Foanaotan mukaan varkauksien toimeenpanijaksi epäiltiin saarilla tuolloin oleskellutta "länsimaista taidekauppiasta", joka karkotettiin Salomonsaarilta näiden epäilyjen vuoksi. Kuitenkaan selkeitä todisteita kaikista syyllisistä ei ollut eikä esineistöä myöskään ole saatu tähän mennessä takaisin. Salomonsaarten poliisi on ollut tilanteessa passiivinen eikä systemaattisia tutkimuksia syyllisten löytämiseksi ole vieläkään tehty.

Olin syksyllä 2007 kolmen kuukauden ajan tekemässä kenttätutkimusta Salomonsaarilla ja jatkamassa 1990-luvun alussa käynnistynyttä tutkimusprojektiani. Tällä kertaa tavoitteenani oli kuvata opiskelijani Jukka Salon kanssa videoaineistoa antropologisia dokumenttielokuvia varten, ja kansallismuseo muodosti yhden dokumentoitavista aihekokonaisuuksista. Tutkimusjakson aikana haastattelimme videolle lähes koko kansallismuseon henkilökunnan. Noissa haastatteluissa kävi ilmi, että vielä tuolloinkaan, kolme vuotta tapahtuneiden murtojen jälkeen, museon henkilöstöllä ei 


\section{JARI KUPIAINEN}

ollut selkeää käsitystä siitä, mitä kaikkea kokoelmista oli viety. Henkilökuntavajeen vuoksi mitään systemaattista inventaariota ei oltu tehty, joten vahinkojen todellinen laajuus oli edelleen selvittämättä.

Omaan taiteita ja käsitöitä käsittelevään väitöskirjatutkimukseeni kytkeytyen olin vuonna 1996 viettänyt kansallismuseon kokoelmien parissa päätoimisesti useita viikkoja. Tuolloin dokumentoin systemaattisesti kaikki museosta löytyvät aineistot, jotka liittyivät omiin tutkimusalueisiini Salomonsaarilla eli yhtäältä Bellonan ja Rennellin saariin ja toisaalta Gatokaen saareen ja Marovo-laguunin alueeseen. Valokuvasin kaikki museon varastosta löytyneet näiden alueiden esineet sekä kopioin kaikki esineluettelot, valokuvaluettelot ja muut aineistot näihin liittyen. Jo tuolloin tilanne oli se, että varastosta ei löytynyt aivan kaikkia niitä esineitä, joita siellä luettelotietojen mukaan olisi pitänyt olla, mutta pääsääntöisesti kokoelmat olivat tallella. Kesä-heinäkuussa 1998 vietin jälleen useita päiviä museon kokoelmien parissa, kun avustin Royal Anthropological Instituten tutkijaa Chris Wrightia rakentamaan museon uuden perusnäyttelyn - joka on edelleen esillä. Tuolloin museon kokoelmat olivat samat kuin kahta vuotta aiemmin enkä havainnut aiemmin dokumentoimistani kokoelmista puuttuvan mitään.

Syksyllä 2007 pääsin jälleen tutustumaan museon varastoon, jolloin havaitsin vahinkojen laajuuden ja luonteen. Tiettyjen saarten esinekokoelmat olivat melko järjestelmällisesti olleet varkauksien kohteina, mutta toisten saarten kokoelmiin ei juuri oltu koskettu, vaikka niihinkin kuului arvokkaita ja esinekulttuurin keräilijöitä kansainvälisesti kiinnostavia esineitä. Havaintojeni perusteella oli ilmeistä, että varkailla oli ollut täsmälliset etukäteistavoitteet, joiden mukaisesti esineitä oli valittu. Esimerkiksi Malaitan, Gela-saarten ja Guadalcanalin alueiden simpukankuorirahat ja muut simpukankuorista valmistetut arvoesineet olivat kadonneet kokonaan. Samoin kokoelmista oli viety lähes kaikki läntisten Salomonsaarten vanhat sotakanoottien keulapatsaat (nguгunguru-patsaat; ks. Kupiainen 2000, 45-64; Waite 1999) sekä tridacnajättiläissimpukankuorista tehdyt harvinaiset barava-levyt ja simpukankuorikoristeiset serubule-sauvat (ks. Kupiainen 1999; 2000; Waite 1983). Minulla ei kuitenkaan ollut mahdollisuutta tehdä mitään omaa inventaariota, vaan kyseessä olivat silmämääräiset havainnot, kuitenkin valokuvien tukemana. Olen sittemmin tarjonnut museolle kopioita vuonna 1996 dokumentoimistani aineistoista, sillä museon henkilöstön mukaan varkauksissa ja tihutöissä sotkettiin myös kokoelmaluetteloita, joista minulla on osittaiset kopiot. Toistaiseksi tähän tarjoukseeni ei ole museossa kuitenkaan reagoitu.

Kesällä 2008 osallistuin European Society for Oceanists -konferenssiin Veronassa, jossa esitelmöin museon tilanteesta ja esitin aiheeseen liittyvän lyhyen dokumenttielokuvan, jonka laajennettu versio on osana tätä artikkelia (Kupiainen 2008). Monet esitystä seuranneet kuulijat olivat eurooppalaisten museoiden kuraattoreita ja muuta henkilökuntaa. Esitykseni jälkeen käydyssä keskustelussa kävi ilmi, että jotkut kuraattoreista olivat viime vuosina törmänneet eri yhteyksissä esineisiin, jotka mitä ilmeisimmin olivat peräisin Salomonsaarten kansallismuseosta ja joita oli tarjottu ostettavaksi. Myös NMSI:n johtaja Lawrence Foanaota oli kuullut (haastattelu lokakuussa 2007), että Uudessa Kaledoniassa oli tarjottu sikäläiseen museoon todennäköisesti Salomonsaarilta varastettuja esineitä. Mitään konkreettisia toimenpiteitä esineiden jäljittämiseksi ja takaisinsaamiseksi ei kuitenkaan oltu tehty. 
VARASTETTU MUSEO, VARASTETTU PERINNE - KYSYMYKSIÄ KULTTUURIPERINNÖN SUOJAAMISESTA MELANESIASSA

\section{HAVAINTOJA SALOMONSAARELAISEN ESINEKULTTUURIN SUOJELUSTA}

Väitöskirjani kenttätutkimuksen jaksoina 1992-93, 1996 ja 1998 kiinnitin systemaattista huomiota vanhan eli esikristillisen ajan esinekulttuurin tilanteeseen tutkimissani yhteisöissä yhtäältä Gatokaen ja toisaalta Bellonan saarella. Samalla kun selvitin paikallisia tilanteita, pyrin eri tavoin kannustamaan paikallisia vielä jäljellä olevien esineiden säilyttämiseen ja suojeluun. Tilanne oli kuitenkin tässä suhteessa hieman lohduton. Kummallakin saarella valtakirkkona olevan seitsemännen päivän adventistikirkon paikallisten oppien mukaan kristillisesti elävien nykysaarelaisten tuli hankkiutua eroon esikristillisen ajan uskomuksista, käytänteistä ja materiaalisista todisteista, joihin kuuluivat vanhat esineet sekä esikristilliset alttarit ja muut uskonnolliset paikat. Jo uskonnollisen kääntymyksen yhteydessä 1938-1939 tuhottiin etenkin Bellonassa lähes kaikki rituaalisesti tärkeät esineet eikä vanhaa Bellonan rituaaliesineistöä juurikaan ole olemassa museoissa tai muissakaan kokoelmissa. Vanhojen esineiden sijasta erityinen huomio Bellonassa onkin liittynyt vanhoihin hautoihin, joihin oli tapana haudata vainajat koruineen ja muine arvoesineineen. Yksittäisiä hautoja on kaivettu viime vuosina auki tällaisten esineiden löytämisen toivossa, mikä on aiheuttanut vilkasta paikallista keskustelua.

Gatokaessa puolestaan tieto saapuvista lähetyssaarnaajista ja uudesta uskonnosta saavutti saaren ennen lähetyssaarnaajia, ja erään enteitä näkevän rituaaliekspertin (mateana) ennustuksen mukaisesti valtaosa rituaaliesineistöstä piilotettiin sisämaan vuoriston kätköpaikkoihin ennen lähetyssaarnaajien saapumista vuonna 1916. Saarelaisten käännyttyä adventisteiksi esineet unohdettiin tai hylättiin kätköpaikkoihinsa. Samalla sisämaasta muodostui kristillisille käännynnäisille vaarallinen paikka, jonne ei käytännössä uskallettu mennä ollenkaan, sillä siellä vanhan uskonnon henkiolennot ja voimat olivat edelleen aktiivisia. Lisäksi uskonnollisen muutoksen myötä paikalliset olivat menettäneet keinot kontrolloida noita voimia, jotka näin olivat muuttuneet villeiksi ja arvaamattomiksi. 1990-luvun kenttätyöjaksojeni aikana sekä kuulin lukuisia kertomuksia että näin osittain itsekin, kuinka etenkin vanhemmat saarelaisista pelkäsivät metsää ja myös pimeän aikaa, jolloin erilaisiin henkiolentoihin saattoi törmätä. Jotkut vanhuksista kulkivat kylästä toiseen lähinnä kahlaamalla saarta ympäröivien koraaliriuttojen reunalla, sillä metsän läpi kulkeville poluille ei uskallettu lähteä. Vastaavasti kuulin nuorempien kyläläisten sarkastisia kommentteja, kuinka eräät vanhuksista liikkuivat pimeän aikaan kahden tai kolmen taskulampun avustamana ja kuinka heidän lampuistaan "patterit eivät olleet koskaan lopussa."

Marovo-laguunin alue on houkutellut etenkin purjeveneillä liikkuvia turisteja ja matkailijoita vähintäänkin 1960-luvulta asti, ja nykysaarelaiset ovat käteisen rahan toivossa kaupitelleet metsien kätköistä löytämiään vanhoja esineitä, erityisesti simpukankuorista valmistettuja rituaali- ja arvoesineitä näille matkailijoille. Vanhojen esineiden maastavienti on muodollisesti kiellettyä, mutta kieltoa ei käytännössä valvota juuri ollenkaan eivätkä kyläläiset ole edes tietoisia tällaisten kieltojen olemassaolosta. Erityisen ongelmallisia tässä suhteessa ovat saarilla vierailevat purjeveneet, sillä ne 


\section{JARI KUPIAINEN}

eivät suinkaan aina ilmoittaudu viranomaisille vaan purjehtivat omaan tahtiinsa alueen halki valtiosta toiseen, jolloin saarilta hankitut esineet vain katoavat yksityiskokoelmiin. Tällainen kaupankäynti oli yleistä 1990-luvulla ja se jatkuu edelleen, kuten havaitsin vieraillessani Gatokaessa syksyllä 2007. Itse asiassa turisteille tarjolla olevien esineiden määrä ja kirjo oli jopa kasvanut 1990-luvun tilanteeseen verrattuna, sillä läntisillä Salomonsaarilla huhtikuussa 2007 tapahtunut voimakas maanjäristys ja sitä seurannut tsunami olivat paljastaneet aiemmin tuntemattomia esinekätköjä. Niiden esineistöä oli tarjolla myös Gatokaessa, vaikka luonnonmullistukset eivät varsinaisesti sinne asti yltäneetkään. Kiinnitin vuoden 2007 vierailuni aikana myös huomiota siihen, että paikalliset esinekauppiaat olivat omaksuneet lisää erilaisia esineiden vanhentamisen ja naamioimisen tekniikoita, joiden tuella pahaa-aavistamattomille turisteille tarjottiin väärennöksiä esikristillisen ajan esineistöstä.

Sekä aiempien kenttätyöjaksojen että erityisesti syksyn 2007 tutkimusjakson aikana puhuin Gatokaessa julkisesti vanhan esinekulttuurin säilyttämisen tärkeydestä ja valistin saarelaisia suositeltavien menettelytapojen suhteen. Käydyissä keskusteluissa toistuivat kerta toisensa jälkeen seuraavat paikalliset argumentit. Yleisesti oltiin tietämättömiä vanhoihin esineisiin liittyvistä myyntikielloista ja rajoituksista esimerkiksi maastaviennin suhteen. Lisäksi vanhoista esineistä haluttiin päästä eroon adventistisen kristillisyyden vaatimuksesta ja samalla näiden esineiden myymistä turisteille pidettiin merkittävänä paikallistason keinona käteisen rahan saamiseksi. Vaikka Salomonsaarten kansallismuseon olemassaolosta ja tehtävistä oltiin yleisellä tasolla tietoisia samoin kuin mahdollisuudesta luovuttaa tai myydä esineitä museoon, tätä mahdollisuutta ei juurikaan arvostettu, sillä museon mahdollisuudet maksaa esineistä "markkinahinta" olivat erittäin rajalliset ja käytännössä olemattomat. Näiden käsitysten tukema paikallinen pragmatismi oli sitä, että periaatteessa kaikki vanha esineistö oli myytävissä, kunhan hinnasta päästiin yksimielisyyteen. Kuitenkin saarelaisten käsitykset vanhojen esineiden hinnasta heilahtelivat villisti, sillä paikallisesti kellään ei ollut realistista käsitystä niistä hinnoista, joilla Salomonsaarten vanhoja esineitä myydään kansainvälisessä artefaktikaupassa. Joko hinnat olivat rajusti alakanttiin tai sitten ne olivat rajusti yläkanttiin verrattuna esineiden kansainväliseen markkina-arvoon ja niihin kohdistuvaan keräilyintressiin (esim. Miller 2006, 136-139; Waite 2008; vrt. Errington 1998; Phillips \& Steiner 1999; Price 2001).

Taide- ja käsityökauppiaat ovat Salomonsaarilla keskittyneet Honiaraan, jossa on lähinnä 1970-luvulta alkaen toiminut lukuisia kauppoja ja gallerioita vaihtelevalla menestyksellä. Osa toimijoista on poistunut markkinoilta muutamassa vuodessa, mutta muutamat liiketoimijat ovat vuosikymmenten mittaan vakiinnuttaneet paikallisten taide- ja käsityömarkkinoiden sekä ammattimaisen käsityötuotannon käytännöt ja toimintamallit Salomonsaarille. 1980-luvulle asti näissä käsityöliikkeissä myytiin vielä suhteellisen yleisesti myös vanhoja perinne-esineitä, mutta seuraavalle vuosikymmenelle tultaessa käsityöliikkeissä alettiin tarjota yhä enemmän vanhoista malleista tehtyjä jäljennöksiä tai replikoita, joiden maastavientiä ei ole rajoitettu. Nykyisin vanhoja esineitä ei ole liikkeissä esillä, mutta oma käsitykseni on, että kauppiailta löytyy monia "kiinnostavia" esineitä takahuoneista ja tiskien alta, mikäli sellaisista on kiinnostunut ja niistä halukas maksamaan. Myöskään tällaisten esineiden maastavienti viranomaisten 
huomaamatta ei ole erityisen vaikeaa. Nämä kaupat ovat vuosikymmenten ajan muodostaneet merkittävän myyntikanavan niille esineille, joita saarelaiset ovat kotikylistään tuoneet Honiaraan myytäväksi. Olen itse lukuisia kertoja ollut todistamassa tilannetta, jossa esinettä tarjotaan ensi museon lunastettavaksi, mutta kun museon tarjoama korvaus ei ole riittänyt, ostajaa on lähdetty etsimään käsityöliikkeistä tai "ekspattien" eli Honiarassa asuvien ulkomaalaisten keskuudesta.

\section{MITÄ OLISI TEHTÄVÄ?}

Yksittäisen ulkomaisen tutkijan keinot vaikuttaa kulttuuriesineistön suojeluun ja säilyttämiseen Salomonsaarilla ovat varsin niukat ja rajallisia ovat myös keinot, joilla saarilta historian eri aikoina eri tavoin viedyt esineet voitaisiin jäljittää - tai palauttaa. Vaikka kansainvälisesti on jo useiden vuosikymmenten ajan käyty vilkasta keskustelua museoesineiden palauttamisen (repatriation) kysymyksistä, esimerkiksi Salomonsaarten suhteen tämä palauttamisen kysymys on ongelmallinen (ks. myös Kupiainen 2004). Salomonsaarten kansallismuseon nykyiset tilat ja toiminnan puitteet eivät tarjoa realistista mahdollisuutta esineiden palauttamiseen. Museolla ei ole riittävästi henkilökuntaa ja resursseja esineiden palauttamisen järjestämiseen eivätkä museon säilytystilat vastaa esineiden pitkäaikaissäilyttämisen ja konservoinnin nykyaikaisia edellytyksiä. Lisäksi museon turvallisuustilanne on puutteellinen, kuten viime vuosien murrot ja kokoelmien ryöstelyt ovat osoittaneet, eikä tilanne ole näiden tapahtumien jälkeenkään juuri muuttunut. Mitään uusia turvajärjestelyjä ei ole tehty eikä viereisellä tontilla sijaitseva Honiaran pääpoliisiasema tunnu tarjoavan museolle erityistä suojaa läheisyydestään huolimatta. Museon alueelle on edelleen helppo tunkeutua huomaamattomasti ja uusien murtojen mahdollisuus on todellinen.

Salomonsaarten viime vuosien poliittiset levottomuudet ja yleinen, jo vuosikymmeniä jatkunut poliittis-hallinnollinen sekavuus selittävät osaltaan sitä, miksi valtiosta puuttuu edelleen nykyaikainen lainsäädäntö kulttuuriperinnön suojaamiseksi. Esimerkiksi lähivaltiot kuten Papua-Uusi-Guinea, Vanuatu tai Samoa ovat liittäneet perinnetiedon, folkloren ja vanhan esinekulttuurin suojan osaksi nykyisiä tekijänoikeuslakejaan, mutta Salomonsaarten tekijänoikeuslakiin ei ole näistä liitetty mainintoja (ks. Papua New Guinea 2000; Solomon Islands 1996; Samoa 1988; Vanuatu 2000). Salomonsaarten kulttuuriperinnön suojaamista säädellään muutamien provinssien omilla säännöksillä, mutta kunnollista valtiontasoista säätelyä ei varsinaisesti ole olemassa. Provinsseista tällaisia säädöksiä on lähinnä Guadalcanalissa ja Läntisessä provinssissa, mutta säännökset eivät yllä suojaamaan vanhojen esineiden käsittelyä tai myyntiä (ks. Lindstrom \& White 1994, Appendix 6 ja 7). Kun samaan aikaan valtiolta puuttuvat tehokkaat keinot yhtäältä valvoa tätä esinekauppaa ja toisaalta valistaa kansalaisia asiassa, ei ole ihme, että suuri osa vanhasta esinekulttuurista on päätynyt yksityisille keräilijöille ja osin satunnaisille matkailijoille Salomonsaarten ulkopuolelle - eikä tilanne näytä olevan muuttumassa. 


\section{JARI KUPIAINEN}

Kansallismuseon toimintaa sätelevä "Solomon Islands National Museum Policy" ei määritä kulttuuriperinnön suojaamista muilta kuin museon omien kokoelmien osalta, ja ohjeisto jättää museolle vieläpä melko väljät toimivaltuudet myös museokokoelman osien myymiseksi (ks. Lindstrom \& White 1994, Appendix 5). Salomonsaarten kansallismuseo on Pacific Islands Museums Associationin (PIMA) jäsen ja kytkeytyy sitä kautta International Council of Museums (ICOM) -järjestöön. Sekä PIMA:n että ICOM:n eettiset koodistot sitovat näin ollen myös Salomonsaarten kansallismuseota (ICOM 2006; PIMA 2006). Nämä eettiset ohjeistot eivät kuitenkaan määritä kansallista lainsäädäntöä Salomonsaarilla vaan ainoastaan ohjeistavat kansallismuseon toimintaa. Museon henkilökunta on ainakin pääsääntöisesti museon toimintaan ja tavoitteisiin sitoutunutta, mutta toimintaresurssien jatkuva niukkuus vaikeuttavat olennaisesti koko museon toimintaa sen kaikilla osa-alueilla. Ylevät eettiset koodistot eivät juuri auta, jos käytännöllisiä mahdollisuuksia niiden velvoitteiden toteuttamiseksi ei ole.

Kansainvälisesti on jo vuosikymmenten ajan pyritty rakentamaan toimintaohjeita ja mallilakeja kulttuuriperinnön suojaamiseksi ja varastettujen kulttuuriaineistojen palauttamiseksi. Keskeisinä toimijoina tässä työssä ovat olleet etenkin UNESCO, UNIDROIT ja World Intellectual Property Organization - WIPO, jotka ovat muotoilleet ohjeistoja ja mallilakeja kansallisten lainsäätäjien avuksi. Tärkeimmät ohjeistot ovat vuosilta 1970, 1985 ja 1995 (UNESCO 1970; UNESCO-WIPO 1985; UNIDROIT 1995). Lisäksi Tyynenmeren saarivaltioiden yhteistoimintajärjestö Secretariat of the Pacific Community (SPC) on vuonna 2002 julkaissut kulttuuriperinnön suojaamisen lainsäädännöllisen mallin, jonka soveltaminen käytäntöön tarjoaisi tehokkaita keinoja sekä perinnetiedon että esinekulttuurin paikalliseksi suojaamiseksi (SPC 2002; 2006). SPC:n mallilaki pohjautuu mainittuihin kansainvälisiin esimerkkeihin. Nämä mallilait ovat sui generis -tyyppisiä suosituksia eikä niillä ole valtioita sitovaa juridista sitovuutta ennen kuin ne on siirretty kansalliseen lainsäädäntöön, mitä esimerkiksi Salomonsaarilla ei ole vielä tehty.

Salomonsaarelaiset paikallisyhteisöt eivät ole kulunutta vuosisataa lukuun ottamatta pohjautuneet kirjalliseen vaan suulliseen historia- ja perinnetietoon. Kristillisen kulttuurinmuutoksen myötä tämän perinnetiedon välittäminen sukupolvelta toiselle on pyritty estämään ja kieltämään. Tämä on toiminut keinona päästä eroon "pakanallisesta" menneisyydestä ja ei-kristillisistä kulttuurisista käytännöistä. Modernisaation, kaupungistumisen ja koululaitoksen myötä etenkin toisen maailmansodan jälkeen syntyneillä sukupolvilla on jo varsin sirpaloitunut tieto ja ymmärrys oman yhteisönsä menneisyydestä ja historiasta. Tämä pitää paikkansa erityisesti niissä yhteisöissä, joissa ei ole tehty systemaattista antropologista ja kulttuurintutkimusta. Sen sijaan muutamat salomonsaarelaisyhteisöt ovat olleet systemaattisen tutkimuksen kohteina ja tyypillisesti näiden yhteisöjen jäsenillä on varsin kattava ymmärrys oman yhteisön menneistä vaiheista. Lisäksi näiden yhteisöjen kulttuurinen identiteetti erottuu Salomonsaarilla muita voimakkaampana. Esimerkkejä tällaisista yhteisöistä ovat vaikkapa tikopialaiset, bellonalaiset ja Malaitan kwaiot, joita käsittelevä tutkimus on ollut vuosikymmenien mittaista ja kattavaa. 
VARASTETTU MUSEO, VARASTETTU PERINNE - KYSYMYKSIÄ KULTTUURIPERINNÖN SUOJAAMISESTA MELANESIASSA

Muistitiedon ohella menneisyyden representaatioita Salomonsaarilla ovat vanhat esineet ja arkeologiset jäänteet, kuten haudat, rakennelmat, alttarit ja muut uhrauspaikat. Enimmät esineet on kuitenkin viety tai myyty pois yhteisöistä, joissa ne on tehty ja niihin liittyvä täsmällinen tietämys on olennaisilta osiltaan kadonnut. Arkeologiset jäänteet ja muut "maastokohteet" ovat puolestaan vuosikymmenten ajan kärsineet sekä ryöstelystä että kontrolloimattomista metsähakkuista, jotka ovat tuhonneet sekä näitä kohteita että niiden ympäristöjä keskeisin tavoin. Metsähakkuut jatkuvat useimmilla saarilla edelleen ja raskaiden metsäkoneiden, useimmiten puskutraktoreiden jäljiltä myös saarten luonto on kokenut suuria vaurioita. Esimerkiksi joet ja muut puhtaan veden lähteet ovat hakkuiden jäljiltä likaantuneet ja maisemat ovat muuttuneet voimakkaasti avohakkuiden seurauksena. Tämän kirjoituksen kannalta erityisen surullisia ovat kuitenkin tuhot arkeologisissa kohteissa. Mikäli esimerkiksi perinteisen uskonnon alttari olisi koskematta, sen analyysi voisi paljastaa kohteen yksilöllisen menneisyyden: kuka paikan on omistanut, kuinka monen sukupolven ajan, miten sitä on käytetty sekä monta muuta tutkijoita - ja myös paikallisia nykyisin kiinnostavaa seikkaa. Lisäksi tällaiset reliikit toimivat esimerkiksi todisteina maanomistuksesta ja -hallinnasta. Ryöstelyn jälkeen paikalle on ehkä jäänyt vain sekalainen kivikasa, joka ei ole enää kenenkään kannalta kiinnostava tai todista mitään erityistä kenellekään. Kaikki paikalliset asukkaat eivät kuitenkaan sure tätä kehitystä. Kuten Gatokaen saarella eräs sinne Malaitalta naimisiin muuttanut mies asian aikanaan (1996) kiteytti: "On vain hyvä, jos vanhat paikat tuhotaan, sillä sitten loppuu myös riitely maanomistuksista, koska väitteitä ei voida todistaa, ja kaikki asukkaat ovat samanarvoisia suhteessa resursseihin."

Salomonsaarten kansallisvaltion rakentaminen on historiallisesti ollut tahmeaa. Nykyvaltio jatkaa kolonialistista prosessia siinä mielessä, että valtio on muodostettu brittiläisen siirtomaahallinnon aikanaan piirtämien maantieteellisten rajojen mukaan. Valtion sisälle jääneillä etnis-kulttuurisilla paikallisyhteisöillä ei välttämättä ole ollut erityisiä yhdistäviä tekijöitä vaan pikemmin konfliktinen paikallishistoria, jossa ryhmät ovat olleet antagonistisissa suhteissa toisiinsa nähden (pääkallonmetsästys, heimosodat). Salomonsaarilla kansallistunne on koko itsenäisyyden ajan ollut ohutta ja yksilöiden solidaarisuus on suuntautunut ennen kaikkea omaan yhteisöön ja oman saaren kulttuurien suuntaan eikä yhteisen valtion tai kansallisen identiteetin rakentamiseen. Tässä kontekstissa kansallismuseo näyttäytyy kansallisena ja lopulta kolonialistisena instituutiona, jonka käynnistäjinä ovat toimineet ulkopuoliset eli eurooppalaiset eivätkä paikalliset toimijat. Koko itsenäisyyden ajan museo on ollut puutteellisesti resursoitu eivätkä poliitikot ole halunneet aktiivisesti kehittää museosta kansallista instituutiota, joka artikuloisi yhteistä kulttuurista menneisyyttä - koska koko yhteisen menneisyyden ajatus on paikallisesti vieras tai ainakin heikosti artikuloitunut. Pikemmin museo on poliitikoille näyttäytynyt "välttämättömänä pahana", jota siedetään kansainvälisistä imagosyistä mutta jota ei todellisuudessa haluta kehittää.

Viime vuosien poliittiset levottomuudet ovat tehneet näkyväksi koko kansallisen kulttuurin ongelmallisen tilan Salomonsaarilla. Mikäli kysymme, miksi viranomaiset ovat suhtautuneet vuoden 2004 ryöstelyihin välinpitämättömästi, on vastausta mielestäni lähdettävä hakemaan tältä suunnalta. Koko valtion olemassaolo 


\section{JARI KUPIAINEN}

oli 2000-luvun alun tapahtumissa vaakalaudalla ja useissa provinsseissa suunniteltiin kansallisvaltiosta irtaantumista. Tässä tilanteessa myös muodostuneen "yhteisen" kulttuuriperinnön purkaminen nousi ajankohtaiseksi: kansallismuseon kokoelmiin kerätyt esinekokoelmat haluttiin oman ryhmän haltuun ja pois hajoavan valtiojärjestelmän hallinnasta. Ironisesti tilannetta voisi kutsua "kulttuuriperinteen dekonstruktioksi", mutta lopulta kyse on menneisyyden hallinnan prosesseista, joista paikallisyhteisöt ovat kokeneet syrjäytyneensä. Tämän kaltaiset ajattelumallit olivat paikallisen väestön keskuudessa tavallisia jo 1990-luvulla, kun keskustelin ihmisten kanssa museosta ja vanhojen esinekokoelmien tilanteesta valtiossa, mutta seuraavalla vuosikymmenellä tilanne on ikävin tavoin konkretisoitunut.

Oma käsitykseni kansallismuseon ryöstöistä on se, että "kansainvälisillä taidekauppiailla" on varmaankin ollut aktiivinen rooli tehtyjen murtojen toimeenpanijoina ja heidän mukanaan varastettuja esinekokoelmia on kulkeutunut kansainvälisille kulttuuriesineiden markkinoille, kuten useat museokuraattorit ovat sittemmin havainnoineet. Varsinaiset murtautujat ovat kuitenkin todennäköisimmin olleet paikallisia ja he ovat samalla poimineet kokoelmista oman yhteisönsä kulttuuriperinnön kannalta arvokkaita esineitä vietäväksi takaisin kotisaarille. Esimerkiksi keskisten Salomonsaarten (Malaita, Guadalcanal, Gela-saaret) simpukankuorirahat ovat nykyisinkin paikallisesti käytettyjä vaihdon välineitä ja tässä suhteessa suoraan verrattavissa käteiseen rahaan. Todennäköisesti nämä museosta varastetut rahakokoelmat ovat osin edelleen Salomonsaarilla ja palanneet osaksi paikallisia taloudellisen vaihdon järjestelmiä.

Salomonsaarten kansallisvaltioon rakenteellisesti kuuluva kansallismuseo asemoituu osaksi historiallista prosessia, jota viime vuosikymmenten tutkimuksessa on tarkasteltu erityisesti kuviteltujen yhteisöjen sekä keksittyihin perinteisiin, kulttuuriperintöön ja museolaitokseen kohdistuvista kriittisistä näkökulmista (esim. Anderson 2007 [1991]; Clifford 1987; 1996; Hobsbawm \& Ranger 1984; Kirschenblatt-Kimblett 1998). Melanesian alueen antropologisessa tutkimuksessa tämä artikuloituu ja paikantuu keskusteluun kastom-käsitteestä ja asemasta melanesialaisissa yhteiskunnissa (ks. esim. Akin 2004; 2005; Babadzan 1988; Keesing 1994; Keesing \& Tonkinson 1982; Lindstrom \& White 1993). Osatiivistelmänä tuosta kirjoittelusta Salomonsaarten pidginin (pijin) käsite kastom edustaa yhteisön omaa käsitystä siitä, mikä kuuluu heidän perinteisiinsä ja kulttuurisiin käytäntöihinsä erotuksena ulkopuolisten, alun perin lähinnä brittiläisten siirtomaavirkailijoiden pyrkimyksiin 1920- ja 30 -luvuilla määritellä paikallisia tapoja englanninkielisellä sanalla "custom" sekä myöhemmin tradition ja kulttuurin käsitteiden avulla. Tässä suhteessa kastom edustaa vastarintaista ja autonomisuutta korostavaa puhe- ja määrittelytapaa perinnettä koskevissa keskusteluissa, joissa ulkopuoliset puhuvat kulttuureista ja traditioista saarelaisten puhuessa kastomista. Nykyisin kastom on monimerkityksinen, rajoiltaan venyvä ja situationaalisesti joustava yleiskäsite, johon kytkeytyy huomattavia paikallisia merkityksiä, jännitteitä ja mikrodiskursseja. Pijinin lisäksi käsite on lokalisoitu useisiin paikallisiin kieliin ja kastom toimii yhteisesti jaettuna käsitteenä koko Salomonsaarilla. (Esim. Jourdan \& Maebiru 2002.)

Salomonsaarten kansallismuseo toimii tradition ja kulttuurin kansainvälisten ja kansallisvaltioon kytkeytyvien "näkökulmien" sekä paikallisen kastom-näkökulman 
VARASTETTU MUSEO, VARASTETTU PERINNE - KYSYMYKSIÄ KULTTUURIPERINNÖN SUOJAAMISESTA MELANESIASSA

rajapinnassa. Se edustaa institutionaalisesti edellisiä tulkiten kansainvälisiä käytäntöjä ja valtiollisia lakeja paikallisiin tilanteisiin sekä kulloisiinkin kastom-käytäntöihin ja määrittelyihin. Museo on salomonsaarelaisena instituutiona "kaikille yhteinen", mutta siihen sitoutuminen on ollut vaillinaista koko itsenäisyyden ajan. Paikallisille yhteisöille keskeistä on kastom, ei niinkään traditio ja kulttuuri. Vaikka merkityserot kuulostavat pieniltä, ne ovat olennaisia: edellinen on omaa, jälkimmäiset institutionalisoivat oman perinteen kansallisvaltion osaksi ja siinä sivussa vielä etäännyttävät sen käsitteelliseen sumuun, joka on vieras. Yhteiskunnan tasolla tämä ilmenee suhteellisena välinpitämättömyytenä kansallismuseota kohtaan ja korostuu nykytilanteessa, kun koko valtio vain vaivoin pysyy koossa edes ulkopuolisten tukemana.

\section{KirjallisuUs}

AKIN, DAVID 2004: Ancestral Vigilance and the Corrective Conscience: Kastom as Culture in a Melanesian Society. Anthropological Theory. 4(3).

AKIN, DAVID 2005: Kastom as Hegemony? A Response to Babadzan. Anthropological Theory. 5(1).

ANDERSON, BENEDICT 2007 (1991): Kuvitellut ybteisöt. Nationalismin alkuperän ja leviämisen tarkastelua. Suom. Joel Kuortti. Tampere: Vastapaino.

BABADZAN, ALAIN 1988: Kastom and Nation Building in the South Pacific. Remo Guidieri, Francesco Pellizzi \& Stanley J. Tambiah (toim.): Ethnicities and Nations. Process of Interethnic Relations in Latin America, Southeast Asia, and the Pacific. Austin: University of Texas Press.

BELLAM, M.E.P. 1970: The Colonial City: Honiara, A Pacific Islands Case Study. Pacific Viewpoint. 11.

BOUTILIER, JAMES 1990: Kennedy's “Army”: Solomon Islanders at War, 19421943. - White, Geoffrey M. \& Lindstrom, Lamont (toim.): The Pacific Theater. Island Representations of World War II. Honolulu: University of Hawaii Press.

BURT, BEN 1994: Tradition and Christianity. The Colonial Transformation of a Solomon Islands Society. Chur: Harwood Academic Publishers.

CHAPMAN, MURRAY 1992: Population Movement: Free of Constrained? - Crocombe, Ron \& Tuza, Esau (toim.): Independence, Dependence, Interdependence. The First 10 Years of Solomon Islands Independence. Honiara: Government Printing Press.

CLIFFORD, JAMES 1988: The Predicament of Culture. Twentieth Century Ethnography, Literature and Art. Cambridge, Ma.: Harvard University Press.

CLIFFORD, JAMES 1997: Routes. Travel and Translation in the Late Twentieth Century. Cambridge, Ma. \& London: Harvard University Press.

FOANAOTA, LAWRENCE 1991: The Solomon Islands National Museum. - Eoe, Soroi M. \& Swadling, Pamela (toim.): Museums and Cultural Centers in the Pacific. Port Moresby: Papua New Guinea National Museum.

FRAENKEL, JON 2005: The Manipulation of Custom. From Uprising to Intervention in the Solomon Islands. Canberra: Pandanus Books. 
JARI KUPIAINEN

GOSDEN, CHRIS \& KNOWLES, CHANTAL 2001: Collecting Colonialism. Material Culture and Colonial Change. Oxford \& New York: Berg.

HOBSBAWM, ERIC \& RANGER, TERENCE T. 1984: The Invention of Tradition. Cambridge: Cambridge University Press.

HVIDING, EDVARD 1996: Guardians of Marovo Lagoon. Practice, Place and Politics in Maritime Melanesia. Honolulu: University of Hawaii Press.

International Council of Museums - ICOM 2006: ICOM Code of Ethics for Museums [online]. < http://icom.museum/ ethics.html > [16.3.2009].

JOURDAN, CHRISTINE with the collaboration by ELLEN MAEBIRU 2002: Pijin. A Trilingual Cultural Dictionary. Canberra: Research School of Pacific and Asian Studies, The Australian National University.

KABUTAULAKA, TARCISIUS TARA 2005: Australian Foreign Policy and the RAMSI Intervention in Solomon Islands. The Contemporary Pacific 17(2).

KEESING, ROGER M. 1987: African Models in the Malaita Highlands. Man 22.

KEESING, ROGER M. 1992: Custom and Confrontation. The Kwaio Struggle for Cultural Autonomy. Chicago: University of Chicago Press.

KEESING, ROGER M. 1994: Colonial and Counter-Colonial Discourse in Melanesia. Critique of Anthropology. 14:1.

KEESING, ROGER M. \& TONKINSON, ROBERT (toim.) 1982: Reinventing Traditional Culture: The Politics of Kastom in Island Melanesia. Mankind. Special Issue. 13(4).

KIRSCHENBLATT-GIMBLETT, BARBARA 1998: Destination Culture. Tourism, Museums, and Heritage. Berkeley: University of California Press.

KUPIAINEN, JARI 1999: Toto isus, Charms and Photos: Visual Ethnography in Gatokae, Western Solomon Islands. SIGHTS - Visual Anthropology Forum. [online] < http://www.joensuu.fi/sights/jari.htm >. Julkaistu 31.5.1999. [16.3.2009].

KUPIAINEN, JARI 2000: Tradition, Trade and Woodcarving in Solomon Islands. Helsinki \& Højbjerg: The Finnish Anthropological Society \& Intervention Press.

KUPIAINEN, JARI 2004: How About a Network Museum? Glowzcewski, Barbara, Pourchez, Laurence, Rostkowski, Joëlle \& Stanton, John (toim.) \& Pourchez, Laurence (koordinointi): Cultural Diversity and Indigenous Peoples. Oral, Written Expressions and New Technologies. CD-ROM. Paris: UNESCO Publishing.

KUPIAINEN, JARI 2008: The Stolen Museum: the National Museum of Solomon Islands Collections in the Ethnic Tension sekä elokuva The Stolen Museum. Esitelmä European Society for Oceanists -konferenssissa "Putting People First': Intercultural Dialogue and Imagining the Future in Oceania", sessio: "Ethnographic Museums at the Beginning of the 21st Century: Stakes and Challenges". Verona 12.7.2008 (julkaisematon).

LARACY, HUGH (toim.) 1983: Pacific Protest. The Maasina Rule Movement Solomon Islands, 1944-1952. Suva: Institute of Pacific Studies, University of the South Pacific.

LINDSTROM, LAMONT \& WHITE, GEOFFREY M. (toim.). 1993: Custom Today. Anthropological Forum, Special Issue. 6(4).

LINDSTROM, LAMONT \& WHITE, GEOFFREY M. (toim.) 1994: CultureKastom-Tradition. Developing Cultural Policy in Melanesia. Suva: Institute of Pacific Studies, University of South Pacific. 
VARASTETTU MUSEO, VARASTETTU PERINNE - KYSYMYKSIÄ KULTTUURIPERINNÖN SUOJAAMISESTA MELANESIASSA

MILLER, JUDITH 2006: Tribal Art. The Essential World Guide. London: Dorling Kindersley.

MOORE, CLIVE 2005: The RAMSI Intervention in the Solomon Islands Crisis. The Journal of Pacific Studies, 28(1).

O'HANLON, MICHAEL \& WELSCH, ROBERT L. 2000: Hunting The Gatherers. Ethnographic Collectors, Agents and Agency in Melanesia, 1870s - 1930s. New York \& Oxford: Berghahn Books.

Pacific Islands Museum Association - PIMA 2006: PIMA Code of Ethics for Pacific Islands

Museums and Cultural Centres. Canberra: Pacific Islands Museum Association. [online] $<$ www.culturepacific.org $/ \mathrm{fr} / \mathrm{bm} / \mathrm{bm} \sim$ doc/pima-code-of-ethics.pdf $>$ [16.3.2009].

Papua New Guinea 2000: Copyright and Neighbouring Rights Act. 21/2000 [online] < http://www.wipo.int/clea/en/details.jsp?id=3427\&tab=2 > [16.3.2009].

PRICE, SALLY 2001 (1989): Primitive Art in Civilized Places. Toinen painos. London \& Chicago: Chicago University Press.

Samoa 1988: Samoa Copyright. 25/1988 [online] < http://www.wipo.int/tk/en//laws/ pdf/samoa_copyright.pdf $>$ [16.3.2009].

Secretariat of the Pacific Community - SPC 2002: Regional Framework for the Protection of Traditional Knowledge and Expressions of Culture. Noumea: Secretariat of the Pacific Community.

Secretariat of the Pacific Community - SPC 2006: Guidelines for Developing National Legislation for the Protection of Traditional Knowledge and Expressions of Culture Based on the Pacific Model Law 2002. Nouméa: Secretariat of the Pacific Community. [online] <http://www.spc.int/Culture/index.htm?meetings_f. htm $\sim$ main $>$ [16.3.2009].

Solomon Islands 1996: Copyright Act. [online] < http://www.paclii.org/sb/legis/ consol_act/ca133/> [16.3.2009].

Summer Institute of Linguistics - SIL 2009: Ethnologue Languages Database: Languages of Solomon Islands. [online] < http://www.ethnologue.com/show_country. asp?name $=\mathrm{SB}>$ [16.3.2009].

THOMAS, NICOLAS 1992: Colonial Conversions: Difference, Hierarchy, and History in Early Twentieth-Century Evangelical Propaganda. Comparative Studies in Society and History. 34(2).

UNESCO 1970: Convention on the Means of Probibiting and Preventing the Illicit Import, Export and Transfer of Ownership of Cultural Property. Paris: UNESCO. [online] < http:/ / portal.unesco.org/en/ev.php-URL_ID=13039\&URL_DO=DO_TOPIC\&URL_ SECTION=201.html $>$ [16.3.2009].

UNESCO \& WIPO 1985: Model Provisions for National Laws on the Protection of Expressions of Folklore Against Illicit Exploitation and Other Prejudicial Actions. Paris: UNESCO \& Geneva: WIPO. [online] < http://unesdoc.unesco.org/ images/0006/000637/063799eb.pdf > [16.3.2009].

UNIDROIT 1995: UNIDROIT Convention on Stolen or Illegally Exported Cultural Objects. Rome: UNIDROIT. [online] < http://www.unidroit.org/english/conventions/1 995culturalproperty/1995culturalproperty-e.htm $>$ [16.3.2009].

Vanuatu 2000: Copyright and Related Rights Act. [online] < http://www.wipo.int/tk/ en/laws/folklore.html > [16.3.2009]. 
JARI KUPIAINEN

WAITE, DEBORAH B. 1983: Form and Function of Tridacna Shell Plaques from the Western Solomon Islands. Empirical Studies of the Arts. 1(1).

WAITE, DEBORAH B. 1999: Toto isu (Nguqunguzu): War Canoe Prow Figureheads from the Western District, Solomon Islands. The World of Tribal Arts. Spring Issue.

WAITE, DEBORAH B. 2008: Solomon Islands Art. - Kevin Conru (toim.): Solomon Islands Art. The Conru Collection. Milan: 5 Continents Editions.

Filosofian tohtori, dosentti Jari Kupiainen toimii yliopettajana Pohjois-Karjalan ammattikorkeakoulun luovien alojen keskuksessa. 